\title{
The Principles of Higher Vocational College Library Literature Resource Construction
}

\author{
Shuiwang Lei \\ Xuzhou College of Industrial Technology, Xuzhou 221140, China. \\ 599281589@qq.com
}

\begin{abstract}
Literature resource construction of higher vocational college library must follow certain principles, only by adhering to these principles, higher vocational college library literature resources construction can be carried out smoothly, from the system principle, practical principle, professional principle, characteristic principle, coordination principle, build sharing principle, standardization principle, development principle, resources construction and service both nine principles of higher vocational college library literature resources construction principle are discussed.
\end{abstract}

Keywords: Higher vocational college; library; literature resource construction; principle.

\section{高职院校图书馆文献资源建设的原则}

\author{
雷水旺 \\ 上徐州工业职业技术学院, 徐州 中国
}

摘 要: 高职院校图书馆文献资源建设必须遵循一定的原则, 只有坚持这些原则, 高职院校图 书馆文献资源建设才能顺利进行，文章从系统性原则、实用性原则、专业性原则、特色化原 则、协调性原则、共建共享原则、标准化原则、发展性原则、资源建设与服务并重原则等九 方面对高职院校图书馆文献资源建设原则进行了探讨。

关键词: 高职院校; 图书馆; 文献资源建设; 原则

\section{1. 前言}

国外对文献资源建设的理论研究并不多, 对高校图书馆文献资源建设的研究主要是研究 新环境下, 特别是网络环境和学习环境 (E-learning) 下的文献资源建设, 注重文献资源建设 的新方法、新技术和共享。高职院校图书馆是高校图书馆的重要组成部分，目前国内对高职 院校图书馆文献资源建设的研究却相对较少。王新刚, 王玉霞、朱新均等提出高职院校图书 馆文献资源建设的原则。

在高职院校图书馆文献资源建设的过程中，必须遵循一定的原则，按照原则进行建设。 这些原则是文献资源建设规律的反映，是对整个建设过程都具有指导作用的基本淮则，只有 坚持这些原则, 高职院校图书馆文献资源建设才能顺利进行。文章结合已有研究成果, 探讨 高职院校图书馆文献资源建设的基本原则。

\section{2. 系统性原则}

高职院校图书馆文献资源建设是一项由多个环节构成的过程更为复杂的系统工程，它有 系统性、完整性、连续性的要求, 因此必须坚持系统性原则。系统性原则体现在三个方面: 文献资源建设应该高屋建瓴, 自成体系, 具有全局的系统性。在文献建设整体上坚持系统性, 在局部建设上也要坚持系统性, 图书馆要系统地收藏高职院校开设专业的文献, 文献资源必 须涵盖本校各专业各学科, 保证各个专业文献的系统收藏。在文献资源建设的类型上也要进 
行系统性建设, 坚持印刷型文献资源, 电子文献资源、网络信息资源及其他载体形式的各类 文献资源的协调发展。

\section{3. 实用性原则}

坚持实用性原则就是指图书馆从实际使用需要出发，规划、选择、收集、管理文献资源， 以最大限度地满足读者对文献信息的需求。它是文献资源建设的基本原则。

高职院校图书馆文献资源必须符合图书馆实际使用的需要，只有符合实际需要，才能被 读者使用, 才能发挥文献资源的实用价值。在阮冈纳赞的《图书馆学五定律》中明确阐述到: “书是为了用的”，这就凸现了文献资源的实用性原则。无论是 “每本书有其读者”，还是 “每个读者有其书”，都体现出文献资源的实用性价值，文献资源如果脱离了用户的实际使 用需要，就不能够为读者使用，就难以实现自身的价值，相对而言也就没什么实用价值。

实用性原则是高职院校图书馆文献资源建设最基本的原则。高职院校图书馆在文献资源 建设中尤其应遵循这一原则, 注重实用性, 坚持以用为主, 以藏为辅, 紧紧围绕服务教学科 研, 把关注点放在追求资源的实用价值上, 放在满足本馆读者的需要上, 切实改变 “重藏轻 用”、“大而全”的旧观念。

\section{4. 专业性原则}

专业性是指针对本校所设置的专业来组织藏书，它反映了学校教学和科研用书的专业范 围和专业特色, 是重点藏书。

专业文献资源是高职院校图书馆的重点文献资源，是图书馆开展专业服务的基础，是满 足学生专业需求的前提。高职院校图书馆应该根据学校的专业设置和课程设置, 全面系统地 收藏相关的文献资源, 一方面要满足学生系统学习专业课程的需要, 另一方面要为教师完成 教学和科研工作提供所需要的专业文献资源。

专业性原则是高职院校图书馆立足高校的前提。高职院校图书馆文献资源建设应坚持专 业性原则, 满足本校专业需求, 保证专业需求。

\section{5. 特色化原则}

特色，是事物所表现的独特风格，是一事物区别于其他事物的显著特征。高职院校图书 馆文献资源特色化, 就是高职院校图书馆的文献资源所具有的独特风格, 具有与其他图书馆 文献资源不同的特点。

《普通高等学校图书馆规程》明确指出：“高等学校图书馆形成具有本馆特色的馆藏体 系。” 特色化原则是文献资源建设的重要原则, 高职院校图书馆文献资源建设要遵循特色化 原则, 形成自己的特色文献资源, 做到 “人无我有, 人有我优” , 否则就不能够突出自己资 源的特色。

特色化建设是高职院校立足于市场的关键所在，高职图书馆文献资源建设要突出特色化。 高职院校图书馆要紧紧围绕学校的办学特色, 根据所开专业和课程, 建立本馆的特色文献资 源, 不要刻意追求各专业资源平衡，应集中有限的人力、资金，重点服务于特色专业, 注重特 色专题数据库建设, 以特色取胜。 ${ }^{[4]}$

\section{6. 协调性原则}

高职院校图书馆文献资源建设作为一个科学体系, 涉及到多种关系, 同图书馆文献资源建 设活动相关的诸多客体发生必然的联系, 高职院校图书馆文献资源建设必须协调好各个方面 的关系，坚持协调发展，协调好印刷型文献资源与电子文献资源的关系，协调好各种载体文 献资源的比例关系, 协调实物馆藏与虚拟馆藏的关系, 协调好资源优势互补与资源共建共享 
的关系, 协调好各学科、各专业的文献资源建设, 协调好一般文献资源和重点文资源献的关 系，协调好各类型文献资源建设经费的分配。

只有坚持协调性原则，才能够使高职院校图书馆文献资源建设具有兼容性与和谐性。

\section{7. 共建共享原则}

共建共享原则是指一个地区、一个系统、一个国家，乃至全球的图书馆之间，图书馆与 其他信息机构之间, 建立广泛的合作关系, 科学规划, 分工写作, 共同建设, 互相提供利用, 建立互相联系、互相依存的信息资源保障体系。

当今社会信息海量增长，然而由于其自身的局限性，任何一个图书馆包藏所有文献资源 都是不可能实现的, 因此高职院校图书馆文献资源建设必须坚持共建共享原则, 走全面合作 的道路，开展广泛的馆际合作与资源共建共享。

\section{8. 标准化原则}

标准化是指电子信息资源著录格式、标引原则、数据指标、符合转换等方面的标准化以 及应用硬件和软件的兼容化。标准化原则是文献资源建设应遵循的原则。

《普通高等学校图书馆规程》明确规定：“必须根据国家的相关规定，实现文献信息资 源加工、组织和管理的标准化。”标准化是保证文献资源建设质量的关键，高职院校图书馆 文献资源建设应该按照标准化原则的要求，注重文献资源建设的标准化和规范化，从而保证 文献资源建设质量。

我们在文献信息资源建设中，一定要严格执行国家标准和国际标准，进一步加强标准化 建设。在标准化建设中, 要注意数据格式、所用代码和通用文献编目规则等要标准化, 统著 录规则、统标引、统软件和统文字录入规则等等, 从而保证数据标准的扩充性、兼容性、可 靠性。

\section{9. 发展性原则}

高职院校图书馆文献资源建设是一个成长着的有机体，在文献资源建设中，应该遵循发 展性原则，有计划、有重点地发展和建设文献资源。

高职院校图书馆文献资源建设既要立足现实，立足校情和馆情，将现实需要和长远发展 相结合, 确保当前图书馆文献资源的顺利发展, 又要着眼于未来，适应未来图书馆事业的发 展, 高职院校图书馆文献资源建设应该具有前瞻性, 只有坚持现实性与超前性相结合的原则, 才能够使图书馆文献资源具有适应性与发展性。

根据本校办学规模、办学水平、学科特色、经费投入、读者服务特点和需求等情况，有 针对地收集、利用和开发各种有价值的文献信息资源, 使文献资源建设与办学规模相匹配, 与高职教育发展重心相适应。

\section{0. 资源建设与服务并重原则}

高职院校图书馆文献资源建设的目的是为了给读者使用，读者的满意率是评价文献资源 建设质量的重要指标。文献资源是图书馆开展服务的物质基础, 离开了文献资源, 图书馆的 服务就成了 “无米之炊” ; 离开了服务, 文献资源就成了 “空中楼阁” ，读者就无法使用资 源, 文献资源建设和服务是相辅相成, 缺一不可, 二者不可偏废, 必须坚持 “两手抓, 两手 都要硬”。

高职院校图书馆文献资源建设的几项原则是一个互相联系、不可分割的统一体。其中， 实用性原则是基本原则，其他几项原则既要以实用性原则为前提，又是实用性原则的保证。 
这些原则全部反映在文献资源建设的全过程, 遵循这些原则, 才能够建立科学合理的高职院 校图书馆文献资源体系。

\section{References}

[1]. Xingang Wang,strengthening the construction of documentary resources of libraries in vocational colleges byapplyingfve principles.journal of anhui vocational college of electronics \&information technologu. Vol. 6 (2007) No. 2, p. 17-18.

[2]. Yinyan Shi.Thoughts on the construction of literature resources in the library of Higher Vocational College.Journal of Hunan Mass Media Vocational Technical College.Vol. 8 (2008) No. 3, p. 93-95.

[3]. Linshan Song.Discussion on Collection Development in Library of Higher Vocational and Technical College.library tribune.Vol. 23 (2003) No. 2, p. 69-71.

[4]. Yinyan Shi.Thoughts on the construction of literature resources in the library of Higher Vocational College.Journal of Hunan Mass Media Vocational Technical College.Vol. 8 (2008) No. 3, p. 93-95.

[5]. Yuxia Wang.On Document Resources Construction in Library in High Vocational College During connotation Development period.Library. (2008) No.5 ,p.106-108. 